\title{
ADALIMUMAB IN THE TREATMENT OF IMMUNE-MEDIATED DISEASES
}

\author{
G. LAPADULA ${ }^{1}$, A. MARCHESONI ${ }^{2}$, A. ARMUZZI ${ }^{3}$, C. BLANDIZZI ${ }^{4}$, R. CAPORALI $^{5}$, \\ S. CHIMENTI ${ }^{6}$, R. CIMAZ ${ }^{7}$, L. CIMINO ${ }^{8}$, P. GIONCHETTI ${ }^{9}$, G. GIROLOMONI ${ }^{10}$, \\ P. LIONETTI ${ }^{11}$, A. MARCELLUSI ${ }^{12}$, F.S. MENNINI ${ }^{12}$, C. SALVARANI ${ }^{13}$
}

'Rheumatology Unit, Interdisciplinary Department of Medicine, Medical School, University of Bari, Bari, Italy; ${ }^{2}$ G. Pini Orthopedic Institute, Piazza A. Ferrari 1, 20122 Milano, Italy

${ }^{3}$ IBD Unit, Complesso Integrato Columbus, Catholic University, Via G. Moscati 31-33 00168 Rome, Italy; ${ }^{4}$ Division of Pharmacology, Department of Clinical and Experimental Medicine, University of Pisa, Pisa, Italy; 'Chair and Division of Rheumatology, IRCCS Policlinico San Matteo Foundation, Pavia, Italy; ${ }^{6}$ Department of Dermatology, University of Rome "Tor Vergata", Rome, Italy; ${ }^{7}$ Department of Paediatrics, Rheumatology Unit, Anna Meyer Children's Hospital, University of Florence, Viale Pieraccini 24, Florence, 50139, Italy; ${ }^{8}$ Ocular Immunology Unit, Ophthalmology Unit, Arcispedale S Maria Nuova Reggio, Viale Risorgimento 80, Reggio Emilia, 42123, Italy

9IBD Unit, Department of Medical and Surgical Sciences, S. Orsola-Malpighi Hospital, University of Bologna, Italy; ${ }^{10}$ Department of Medicine, Section of Dermatology and Venereology, University of Verona, Verona, Italy; "Gastroenterology Unit, Anna Meyer Children's Hospital, Department of Paediatrics, University of Firenze, Viale Peraccini 24, 50139, Florence, Italy; ${ }^{2}$ CEIS-Economic Evaluation and HTA (EEHTA), IGF Department, University of Tor Vergata, Rome, Italy; '"Rheumatology Unit, Department of Internal Medicine, Azienda Ospedaliera ASMN, Istituto di Ricovero e

Cura a Carattere Scientifico, Viale Risorgimento 80, Reggio Emilia, 42123, Italy

Tumour necrosis factor (TNF) plays an important role in the pathogenesis of immune-mediated inflammatory diseases (IMIDs). TNF inhibition results in down-regulation of abnormal and progressive inflammatory processes, resulting in rapid and sustained clinical remission, improved quality of life and prevention of target organ damage. Adalimumab is the first fully human monoclonal antibody directed against TNF. In this article, we review the role and cost effectiveness of adalimumab in the treatment of IMIDs in adults and children. The efficacy and tolerability of adalimumab has been demonstrated in patients with a wide range of inflammatory conditions, leading to regulatory approval in rheumatoid arthritis (RA), psoriatic arthritis (PsA), plaque psoriasis, inflammatory bowel diseases (Crohn's disease, ulcerative colitis, paediatric Crohn's disease, and intestinal Behçet's disease), ankylosing spondylitis (AS), axial spondyloarthritis (SpA) and juvenile idiopathic arthritis. The major tolerability issues with adalimumab are class effects, such as injection site reactions and increased risk of infection and lymphoma. As with all anti-TNF agents, adalimumab is immunogenic, although less than infliximab, and some patients receiving long-term adalimumab will develop anti-drug antibodies, causing a loss of response. Comparisons of its clinical utility and cost effectiveness have shown it to be a valid treatment choice in a wide range of patients. Recent data from Italian economic studies show the cost effectiveness

Keywords: Adalimumab, tumour necrosis factor (TNF), immune-mediated disorders, anti-TNF therapy

Mailing address:

Dr Antonio Marchesoni,

G. Pini Orthopedic Institute,

Piazza A. Ferrari 1, 20122 Milano, Italy.

Tel: +390258296415; Fax: +390258296495;

E-mail: marchesoni@gpini.it
0394-6320 (2014) Copyright 0 by BIOLIFE, s.a.s. This publication and/or article is for individual use only and may not be further reproduced without written permission from the copyright holder. Unauthorized reproduction may result in financial and other penalties DISCLOSURE: ALL AUTHORS REPORT NO CONFLICTS OF INTEREST RELEVANT TO THIS ARTICLE. 
of adalimumab to be below the threshold value for health care interventions for most indications. In addition, analysis of indirect costs shows that adalimumab significantly reduces social costs associated with RA, PsA, AS, Crohn's disease and psoriasis. The fact that adalimumab has the widest range of approved indications, many often presenting together in the same patient due to the common pathogenesis, may further improve the utility of adalimumab. Current clinical evidence shows adalimumab to be a valuable resource in the management of IMIDs. Further research, designed to identify patients who may benefit most from this drug, will better highlight the role and cost-effectiveness of this versatile TNF inhibitor.

Immune-mediated inflammatory disease (IMID) is the designation given to a range of inflammatory disorders that share common pathogenic pathways and a dysregulation of inflammatory cytokines (1). Indeed, some chronic inflammatory disorders share overlapping epidemiological, pathogenic, and genetic features $(2,3)$, and have been shown to cluster (i.e. the presence of one disease confers an increased risk of developing others) in some patients and families. Examples of these combinations include psoriasis, psoriatic arthritis (PsA) and Crohn's disease (46), rheumatoid arthritis (RA) and ulcerative colitis (UC) (7-10), arthropathies and inflammatory bowel disease (IBD; Crohn's disease or UC) (11) and spondyloarthropathies (SpA), PsA and IBD (12).

The cytokine tumour necrosis factor (TNF) plays an important role in the pathogenesis of these chronic inflammatory conditions and immune-mediated disorders $(13,14)$. The inhibition of TNF results in a down-regulation of the abnormal inflammatory pathways implicated in the pathogenesis and progression of IMIDs (15). Biologic response modifiers targeting TNF - comprising the class of anti-TNF biotechnological drugs - employed as monotherapy or in combination with other immunosuppressive or anti-inflammatory therapies, have been shown to provide rapid and sustained clinical remission, improved quality of life $(\mathrm{QoL})$, prevention of disease progression and, in many cases, resolution of target organ damage under chronic conditions $(16,17)$.

Inference from the latest EULAR guidelines for treatment of rheumatic diseases with biologic agents suggests that the ideal anti-TNF agent should be effective in alleviating symptoms and preventing radiographic progression of structural damage, and capable of inducing clinical remission (or even reversing the existing damage), with rapid onset of action, persistent effect (no tolerance effect [i.e. low immunogenicity]) and benign tolerability. It should also be convenient and easy to administer, cost effective, and suitable for use in all patient populations, including the elderly, children and those with renal and hepatic impairment (16). Although the ideal anti-TNF drug does not yet exist, among the available anti-TNF agents, adalimumab, the first fully human $\mathrm{IgG}_{1}$ monoclonal antibody directed against TNF, has many attributes that make it a valid clinical choice for long-term treatment of rheumatic diseases.

Adalimumab binds TNF bivalently, to form multimeric 'antigen-antibody' complexes, thus preventing TNF from activating cell surface TNF receptors, thereby modulating the biological activities regulated by TNF (14). By comparison, infliximab is a chimeric mouse-human IgG $_{1}$ monoclonal antibody and golimumab is a fully human $\mathrm{IgG}_{1}$ monoclonal antibody, and both bind TNF bivalently. Etanercept, on the other hand, is a TNF receptor-IgG fusion protein, which consists of the constant $\mathrm{Fc}$ fragment of human $\mathrm{IgG}_{1}$ connected by a hinge region to two extracellular domains of the human TNF receptor (TNFR) (18), and forms a monovalent bond with TNF. Certolizumab pegol comprises a single $\mathrm{IgG}_{1}$ Fab' fragment of a humanized monoclonal antibody bound to two $20 \mathrm{kD}$ polyethylene glycol chains, which extend the plasma half-life of the drug (19). Since it is not equipped with an Fc region, certolizumab interacts with TNF in a monovalent fashion $(20,21)$.

\section{Objective and methodology}

The aim of this narrative review is to discuss the place of adalimumab in the treatment of IMIDs in adults and children, as well as to review economic data on its potential to provide a cost effective treatment option compared with other existing treatments, with particular focus on the economics 
of its multi-indication role in the treatment of patients with more than one IMID. Combined automated and manual literature searches were performed in PubMed using the search terms 'adalimumab' AND 'immune-mediated disease/disorders' AND ['children' OR pediatric/paediatric' OR 'adolescent' OR 'cross-indication' OR 'disease association' OR 'cost' OR 'economic' or 'pharmacoeconomic']. From the resulting papers, manual searches were performed to find relevant papers on adalimumab in the treatment of immune-mediated disease/disorders.

\section{Current role of adalimumab}

Adalimumab was first approved for treatment of RA in 2002 and is now indicated for the treatment of a wide range of IMIDs (Table 1) (22). The efficacy and tolerability of adalimumab has been demonstrated in several pivotal trials in patients with a wide range of inflammatory conditions such as $\operatorname{RA}(23,24), \operatorname{AS}(25$, 26), axial spondyloarthritis (SpA) (27), PsA $(26,28)$, plaque psoriasis $(29,30)$, Crohn's disease $(31,32)$, UC $(33,34)$ and JIA (12). The clinical data obtained in these trials have been reviewed in another paper in this supplement.

The major safety and tolerability issues with adalimumab include mostly class effects, such as injection site reactions, increased infection risk (serious infections, tuberculosis and opportunistic infections), lymphoma, and other rare events, including demyelinating disease, autoimmune phenomena, hematologic toxicities, and congestive heart failure $(35,36)$. A large cross-indication analysis of adalimumab safety data, from almost 12 years of adalimumab exposure in clinical trials, showed that the most frequently reported serious adverse events (SAEs) were infections, with the greatest incidence reported in studies of patients with RA and Crohn's disease (37). Although the overall malignancy rates were similar to those in the general population, the incidence of lymphoma was increased in patients with RA, and the incidence of non-melanoma skin cancer was raised in RA, psoriasis and Crohn's disease (37).

\section{Immunogenicity}

As with all anti-TNF agents, adalimumab is immunogenic, and over time patients develop antidrug antibodies (ADAs) to adalimumab, which eventually cause tolerance - a reduction in the pharmacological activity leading to a reduced efficacy and a need for dose escalation $(38,39)$. ADAs, reported particularly with infliximab, are seen to a lesser extent with adalimumab, occurring in approximately $20-28 \%$ of patients receiving long-term adalimumab treatment (40). In addition to reduced efficacy, ADAs are also associated with safety issues such as anaphylaxis or vasculitis (41). Combination therapy with non-biologic disease modifying antirheumatic drugs (DMARDs), particularly methotrexate (MTX), seems to reduce the occurrence of ADA formation $(40,42)$. Studies assessing immunogenicity, to determine optimal treatment regimens and concomitant immunosuppressant therapy to minimize ADA formation or to investigate the use of neutralizing immunotherapy to reduce the likelihood of ADA development, are ongoing $(39,43)$. In addition to being dependent on the specific anti-TNF agent used, immunogenicity and ADA formation appear to be associated with the mode of administration and regimen used $(40,44,45)$. Generally, subcutaneous administration is more immunogenic than intravenous, due to the smaller volumes used, slower distribution and greater variability of interindividual drug exposure (45). The likelihood of ADA formation also appears to be reduced with continuous maintenance therapy compared with intermittent or sporadic treatment (44). ADA formation may also be dependent on the underlying disease, with higher ADA levels observed in RA, Crohn's disease and PsA; although this may simply be due to an increased exposure to biologics or a greater number of clinical studies in these patient populations.

A range of analytical assays, such as enzymelinked immunosorbent assay (ELISA) and radioimmunoassay (RIA), have been used to detect and measure ADAs; however, the ADA titre can vary according to the type of assay used and is confounded by the presence of circulating anti-TNF antibodies and rheumatoid factor. Accordingly, the reported prevalence of ADAs can vary substantially (44) (Table 2).

\section{IMID cross-indications}

Among the available TNF antagonists etanercept, infliximab, adalimumab, certolizumab 
Table 1. Adalimumab indications according to labelling (2I)

\begin{tabular}{|c|c|c|}
\hline Indication & $\begin{array}{l}\text { Approval date } \\
\text { (country) }\end{array}$ & Details \\
\hline $\begin{array}{l}\text { Rheumatoid arthritis } \\
\text { (RA) }\end{array}$ & $\begin{array}{l}\text { Dec } 2002 \text { (USA) } \\
\text { Sept } 2003 \\
\text { (Europe) }\end{array}$ & $\begin{array}{l}\text { In combination with MTX: } \\
\text { Moderate to severe, active RA in adult patients when the response to } \\
\text { DMARDs including MTX has been inadequate } \\
\text { Severe, active and progressive RA in adults not previously treated with } \\
\text { MTX } \\
\text { Can be given as monotherapy in case of intolerance to MTX or when } \\
\text { continued treatment with MTX is inappropriate }\end{array}$ \\
\hline $\begin{array}{l}\text { Polyarticular juvenile } \\
\text { idiopathic arthritis } \\
\text { [JIA] }\end{array}$ & $\begin{array}{l}\text { Feb } 2008(\text { USA) } \\
\text { Sept } 2008 \\
\text { (Europe) }\end{array}$ & $\begin{array}{l}\text { In combination with MTX: } \\
\text { Children and adolescents } 4 \text { to } 17 \text { years who have had an inadequate } \\
\text { response to one or more DMARDs; can be given as monotherapy in case } \\
\text { of intolerance to MTX or when continued treatment with MTX is } \\
\text { inappropriate }\end{array}$ \\
\hline $\begin{array}{l}\text { Ankylosing spondylitis } \\
\text { (AS) and axial } \\
\text { spondyloarthritis } \\
(\mathrm{AxSp})\end{array}$ & $\begin{array}{l}\text { AS: Jun } 2006 \\
\text { (Europe); Jul } \\
2006 \text { (USA) } \\
\text { AxSp: Jul } 2012 \\
\text { (Europe) }\end{array}$ & $\begin{array}{l}\text { Adults with severe active AS who have had an inadequate response to } \\
\text { conventional therapy } \\
\text { AxSp without radiographic evidence of AS } \\
\text { Severe AxSp without radiographic evidence of AS but with objective } \\
\text { signs of inflammation by elevated CRP and/or MRI, with inadequate } \\
\text { response to, or intolerant to NSAIDs }\end{array}$ \\
\hline $\begin{array}{l}\text { Psoriatic arthritis } \\
\text { (PsA) }\end{array}$ & $\begin{array}{l}\text { Aug } 2005 \\
\text { (Europe) } \\
\text { Dec } 2005 \text { (USA) }\end{array}$ & $\begin{array}{l}\text { Active and progressive PsA in adults when the response to previous } \\
\text { DMARDs has been inadequate }\end{array}$ \\
\hline Plaque psoriasis & $\begin{array}{l}\text { Dec } 2007 \\
\text { (Europe) }\end{array}$ & $\begin{array}{l}\text { Moderate to severe chronic plaque psoriasis in adult patients who failed } \\
\text { to respond to or who have a contraindication to, or are intolerant to other } \\
\text { systemic therapy including cyclosporine. MTX or PUVA }\end{array}$ \\
\hline Crohn's disease & $\begin{array}{l}\text { Feb } 2007 \text { (USA) } \\
\text { Jun } 20007 \\
\text { (Europe) }\end{array}$ & $\begin{array}{l}\text { Moderately to severely active Crohn's disease, in adult patients who } \\
\text { have not responded despite a full and adequate course of therapy with a } \\
\text { corticosteroid and/or an immunosuppressant; or who are intolerant to or } \\
\text { have medical contraindications for such therapies }\end{array}$ \\
\hline $\begin{array}{l}\text { Paediatric Crohn's } \\
\text { disease }\end{array}$ & $\begin{array}{l}\text { Nov } 2012 \\
\text { (Europe) }\end{array}$ & $\begin{array}{l}\text { Moderately to severely active Crohn's disease, in children who have not } \\
\text { responded despite a full and adequate course of therapy with a } \\
\text { corticosteroid and/or an immunosuppressant; or who are intolerant to or } \\
\text { have medical contraindications for such therapies }\end{array}$ \\
\hline Ulcerative colitis (UC) & $\begin{array}{l}\text { April } 2012 \\
\text { (Europe) } \\
\text { Sept } 2012 \text { (USA) }\end{array}$ & $\begin{array}{l}\text { Moderately to severely active UC in adult patients who have had an } \\
\text { inadequate response to conventional therapy including corticosteroids } \\
\text { and 6-mercaptopurine or azathioprine, or who are intolerant to or have } \\
\text { medical contraindications for such therapies }\end{array}$ \\
\hline $\begin{array}{l}\text { Intestinal Behçet’s } \\
\text { disease }\end{array}$ & May 2013 (Japan) & $\begin{array}{l}\text { Intestinal Behçet's disease (Behçet's disease accompanied by intestinal } \\
\text { ulcer) in adults refractory to conventional therapies }\end{array}$ \\
\hline
\end{tabular}

CRP, C-reactive protein; DMARD, disease-modifying antirheumatic drug; MRI, magnetic resonance imaging; MTX, methotrexate; NSAID, non-steroidal anti-inflammatory drug; PUVA, psoralen-ultraviolet A combination therapy. 
Table 2. Frequency of anti-drug antibody (ADA) development reported with anti-tumour necrosis factor (anti-TNF) therapies (44)

\begin{tabular}{|c|c|c|}
\hline Drug & Indication & Prevalence reported (\% patients) \\
\hline \multirow[t]{5}{*}{ Adalimumab } & RA & $0.72-87 \%$ \\
\hline & $\overline{\mathrm{AS}}$ & $31 \%$ \\
\hline & $\overline{P s A}$ & $18 \%$ \\
\hline & Psoriasis & $6-45 \%$ \\
\hline & Crohn's disease & $0.04-17 \%$ \\
\hline \multirow[t]{6}{*}{ Infliximab } & RA & $10-50 \%$ \\
\hline & $\mathrm{SpA}$ & $15.4-25.5 \%$ \\
\hline & AS & $18-29 \%$ \\
\hline & Crohn's disease & $6-61 \%$ \\
\hline & PsA & $15.4 \%$ \\
\hline & Psoriasis & $19.5-51.5 \%$ \\
\hline \multirow[t]{4}{*}{ Etanercept } & RA & $0-5.6 \%$ \\
\hline & AS & 0 \\
\hline & PsA & 0 \\
\hline & Psoriasis & $1.1-18.3 \%$ \\
\hline \multirow[t]{3}{*}{ Golimumab } & RA & $0-7 \%$ \\
\hline & AS & $1.44 .1 \%$ \\
\hline & PsA & $4.6-4.9 \%$ \\
\hline \multirow[t]{3}{*}{ Certolizumab } & RA & $5-8.1 \%$ \\
\hline & Psoriasis & $4-25 \%$ \\
\hline & Crohn's disease & $3.1-17.7 \%$ \\
\hline
\end{tabular}

AS, ankylosing spondylitis; PSA, psoriatic arthritis; RA, rheumatoid arthritis; SpA, spondyloarthropathy.

pegol and golimumab - adalimumab has the widest employment, having been approved for use in nine separate IMID indications (RA, PsA, SpA/ AS, Crohn's disease, paediatric Crohn's, UC, JIA, psoriasis and intestinal Behçet's disease). Within these indications, IMIDs that have been reported in the same patient include peripheral arthropathies + IBD (46-48), RA + IBD (7-10, 42, 49), RA + paediatric UC + Crohn's disease (50), IBD + psoriasis $(4,6,49)$ and PsA + psoriasis + IBD (5). 
Table 3. Clinical studies of adalimumab in patients with two or more immune-mediated disorders

\begin{tabular}{|c|c|c|c|c|c|c|c|}
\hline $\begin{array}{l}\text { Reference (study } \\
\text { acronym) }\end{array}$ & Indications & Design & $N$ & \begin{tabular}{|l|} 
Treatment \\
\end{tabular} & \begin{tabular}{|l} 
Endpoints \\
\end{tabular} & Efficacy outcomes & Tolerability \\
\hline Andrisani et al. (42) & $\begin{array}{l}\text { Seronegative } \\
\text { erosive RA + } \\
\text { refractory UC }\end{array}$ & Case study & $\begin{array}{l}\text { 1.54-yr-old } \\
\text { female }\end{array}$ & $\begin{array}{l}\text { Adalimumab } \\
160 / 80 \mathrm{mg} \mathrm{wk} \\
0 / 2 \text {. then } 40 \mathrm{mg} \\
\text { eow }\end{array}$ & NA & $\begin{array}{l}\text { Complete remission } \\
\text { after } 1 \mathrm{yr}\end{array}$ & NR \\
\hline $\begin{array}{l}\text { Braun el al. (52) } \\
\text { (RHAPSODY) }\end{array}$ & AS \pm psoriasis & P.OL & $\begin{array}{l}1250 \text { (148 with } \\
\text { psoriasis }\end{array}$ & $\begin{array}{l}\text { Adalimumab } 40 \\
\text { mg cow for } 12 \\
\text { wks }\end{array}$ & $\begin{array}{l}\text { ASAS40, } \\
\text { BASDAI50 }\end{array}$ & 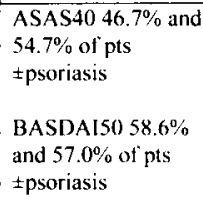 & $\begin{array}{l}\text { No correlation of } \\
\text { skin changes with } \\
\text { AS efficacy }\end{array}$ \\
\hline Kotaniemi et al. (55) & $\mathrm{JIA}$ and uveitis & P.OL & 94 & Adalimumab & $\begin{array}{l}\text { Uveitis SUN } \\
\text { activity, arthritis } \\
\text { activily }\end{array}$ & $\begin{array}{l}\text { SUN } 2 \times \text { reduction } \\
\text { (good response) in } \\
28 \% \text {, moderate } \\
17 \% \text {, no change } \\
17 \% \text { and worsening } \\
\text { in } 13 \%\end{array}$ & NR \\
\hline $\begin{array}{l}\text { Lofberg et al. (46) } \\
\text { (CARE) }\end{array}$ & $\begin{array}{l}\text { Moderate-to-severe } \\
\text { CD + extraintestinal } \\
\text { manifestations } \\
\text { (EIMS) }\end{array}$ & P. OA. MC & $\begin{array}{l}945 \text { (497 with } \\
\text { EIM) }\end{array}$ & $\begin{array}{l}\text { Adalimumab } \\
160 / 80 \mathrm{mg} \mathrm{wk} \\
0 / 2 \text {, then } 40 \mathrm{mg} \\
\text { eow }\end{array}$ & $\begin{array}{l}\text { Remission rate } \\
\mathrm{HBI}<5\end{array}$ & $\begin{array}{l}\text { Wk } 20 \text { CD } \\
\text { remission rate 52\%: } \\
51 \% \text { with EIM free } \\
\text { of EIM S\&S }\end{array}$ & $\begin{array}{l}\text { Serious infections } \\
5 \% \text {; well tolerated }\end{array}$ \\
\hline Moretti et al. (56) & $\begin{array}{l}\text { Psoriatic JIA and } \\
\text { uveitis }\end{array}$ & Case report & 1 & Adalimumab & NA & $\begin{array}{l}\text { Sustained remission } \\
\text { in } J I A \text { and uveitis }\end{array}$ & $\mathrm{NR}$ \\
\hline $\begin{array}{l}\text { Rudwaleit et al. (53) } \\
\text { (RHAPSODY) }\end{array}$ & $\begin{array}{l}\text { AS and peripheral } \\
\text { arthritis and } \\
\text { enthesitis }\end{array}$ & P.OL & $\begin{array}{l}1250 \text { (686 with } \\
\text { enthesitis and } \\
281 \text { with } \\
\text { peripheral } \\
\text { arthritis) }\end{array}$ & $\begin{array}{l}\text { Adalimumab } 40 \\
\text { mg eow for } 12 \\
\text { wks }\end{array}$ & ASAS20, MASES & $\begin{array}{l}\text { Improvement in } \\
\text { MASES ASAS20 } \\
\text { in } 66.7-71 \% \text { of pts }\end{array}$ & $\mathrm{NR}$ \\
\hline $\begin{array}{l}\text { Rudwaleit et al. (47) } \\
\text { (RHAPSODY) }\end{array}$ & AS and uveitis & P.OL & $\begin{array}{l}1250 \text { ( } 45 \mid \text { with } \\
\text { uveitis or } h / o \\
\text { uveitis) }\end{array}$ & $\begin{array}{l}\text { Adalimumab } 40 \\
\text { mg eow for } 20 \\
\text { wks }\end{array}$ & $\begin{array}{l}\text { Rate of uveitis } \\
\text { flares }\end{array}$ & $\begin{array}{l}\text { Wk } 20 \text { rate of } \mathrm{AU} \\
\text { flares reduced by } \\
45-68 \%\end{array}$ & NR \\
\hline $\begin{array}{l}\text { Van der Heijde et al. } \\
\text { (58) }\end{array}$ & $\begin{array}{l}\text { AS (some pts with } \\
\text { uveitis. }\end{array}$ & $\mathrm{RCT}$ & $\begin{array}{l}315 \text { (95 with } \\
\text { uveitis, } 33 \text { with } \\
\text { psoriasis) }\end{array}$ & $\begin{array}{l}\begin{array}{l}\text { Adalimumab } \\
(\mathrm{n}=208)\end{array} \\
\mathrm{PBO}(\mathrm{n}=107)\end{array}$ & $\begin{array}{l}\text { ASAS20, BASFI, } \\
\text { BASDAI, } \\
\text { BASMI }\end{array}$ & $\begin{array}{l}\text { ASA20 58.2\% with } \\
\text { Adalimumab, and } \\
20.6 \% \text { with PBO }\end{array}$ & $\begin{array}{l}\text { AEs: } 75 \% \text { (ADA) } \\
\text { vs } 59.8 \% \text { (PBO) } \\
\text { Injection sitc } \\
\text { reactions: } 10.1 \% \text { vs } \\
2.8 \%\end{array}$ \\
\hline Yildizet al. (57) & AS and Behçet's & Case study & 1, 44-yr-old male & $\begin{array}{l}\text { Adalimumab } 40 \\
\text { mg eow }\end{array}$ & $\mathrm{NA}$ & $\begin{array}{l}\text { Remission of AS } \\
\text { and } \mathrm{BD}\end{array}$ & $\overline{\mathrm{NR}}$ \\
\hline Zannin et al. (54) & $\mathrm{JIA}$ and $\mathrm{AU}$ & $\begin{array}{l}\text { Observational } \\
\text { registry }\end{array}$ & $\begin{array}{l}108 \text { (91 with } 12- \\
\text { mo follow-up) }\end{array}$ & $\begin{array}{l}\begin{array}{l}\text { Adalimumab } \\
(\mathrm{n}=43)\end{array} \\
\text { IFX }(\mathrm{n}=48)\end{array}$ & $\begin{array}{l}\text { Change in uveitis } \\
\text { course and in } \\
\text { number of ocular } \\
\text { complications }\end{array}$ & $\begin{array}{l}\text { AU remission } \\
55.3 \% \\
\text { (Adalimumab } \\
67.4 \% \text {. IFX } 42.8 \% \text {; } \\
\mathrm{p}=0.025 \text { ) } \\
\text { Reduction in ocular } \\
\text { complications }\end{array}$ & $\begin{array}{l}\text { No SAEs } \\
\text { Minor AE in } 8.8 \% \\
\text { (1IAes. } 9 \text { with IFX } \\
\text { and } 2 \text { with } \\
\text { Adalimumab) }\end{array}$ \\
\hline
\end{tabular}

AS, ankylosing spondylitis; ASAS20, $\geq 20 \%$ improvement in Assessment of Ankylosing Spondylitis response criteria; $A U$, anterior uveitis; BASFI, Bath Ankylosing Spondylitis Functional Index; BASDAI, Bath Ankylosing Spondylitis Disease Activity Index; BASMI, Bath Ankylosing Spondylitis Metrology Index; BD, Behçet 's disease; CD. Crohn's Disease; DB, double-blind; EIM, extraintestinal manifestations; eow, every other week; HBI, Harvey-Bradshaw Index; h/o, history of: IFX, infliximab; MASES, Maastricht ankylosing spondylitis enthesitis score; MC, multicentre; NA, not applicable; NR, not reported; $O L$, open-label; P, prospective; $P B O$, placebo; PC, placebo-controlled; pts, patients; $R$, randomised; $R A$, rheumatoid arthritis; $R C T$, randomised controlled trial; S\&S, signs and symptoms; SUN, Standardized Uveitis Nomenclature; UC, ulcerative colitis; JIA, juvenile idiopathic arthritis 
Table 4. Adalimumab ongoing/unpublished trials in off-label indications [Source: ClinicalTrials.gov]

\begin{tabular}{|c|c|c|c|c|c|c|c|c|}
\hline $\begin{array}{l}\text { ClinicalT rial.gov } \\
\text { number (Study } \\
\text { acronym) }\end{array}$ & Indications & Design & Status & Phase & Treatment & Primary endpoint & Estimated N & $\begin{array}{l}\text { Estimated } \\
\text { study } \\
\text { completion } \\
\text { date }\end{array}$ \\
\hline $\begin{array}{l}\text { NCT01138657 } \\
\text { VISUAL 1 }\end{array}$ & Active uveitis & $\begin{array}{l}\text { R. DB.PC. } \\
\text { MC }\end{array}$ & Recruiting & III & $\begin{array}{l}\text { Adalimumab } \\
\text { Prednisone } \\
\text { PBO }\end{array}$ & Time to treatment failure & 250 & Nov 2014 \\
\hline $\begin{array}{l}\text { NCT01124838 } \\
\text { VISUAL II }\end{array}$ & Inactive uveitis & $\begin{array}{l}\text { R, DB, PC, } \\
\text { MC }\end{array}$ & Recruiting & III & $\begin{array}{l}\text { Adalimumab } \\
\text { Prednisone } \\
\text { PBO }\end{array}$ & Time to treatment failure & 250 & Oct 2014 \\
\hline $\begin{array}{l}\text { NCT01148225 } \\
\text { VISUAL III }\end{array}$ & $\begin{array}{l}\text { Non-infectious } \\
\text { uveitis }\end{array}$ & MC. OL & $\begin{array}{l}\text { Enrolling by } \\
\text { invitation only }\end{array}$ & III & $\begin{array}{l}\text { Adalimumab } \\
\text { Prednisone } \\
\text { PBO }\end{array}$ & $\begin{array}{l}\text { AEs, Lab parameters and } \\
\text { vital signs }\end{array}$ & 400 & Mar 2016 \\
\hline NCT00274352 & $\begin{array}{l}\text { Cutaneous } \\
\text { sarcoidosis }\end{array}$ & $\begin{array}{l}R, C O, P C \\
D B\end{array}$ & Completed & II & Adalimumab & $\begin{array}{l}\text { Week-12 responders (pts } \\
\text { achieved at least a } \\
\text { moderate improvement on } \\
\text { PGA) }\end{array}$ & 16 & $\begin{array}{l}\text { Feb } 2012 \text { (not } \\
\text { yet published) }\end{array}$ \\
\hline NCT01166282 & $\begin{array}{l}\text { Enthesitis-related } \\
\text { JIA }\end{array}$ & R, DB, PC & $\begin{array}{l}\text { Active, not } \\
\text { recruiting }\end{array}$ & 111 & $\begin{array}{l}\text { Adalimumab } \\
\text { PBO }\end{array}$ & $\begin{array}{l}\% \text { change in number of } \\
\text { active joints; AEs }\end{array}$ & 45 & $\operatorname{Dec} 2015$ \\
\hline $\begin{array}{l}\text { NCT01219257 } \\
\text { ULSPABIT } \\
\text { (extension of } \\
\text { NORDMARD study) }\end{array}$ & Spondyloarthritis & $\begin{array}{l}\text { Prospective, } \\
\text { observational }\end{array}$ & Unknown & $\mathrm{NR}$ & Anti-TNF & $\begin{array}{l}\text { Sensitivity to change of US } \\
\text { pathology in joints and } \\
\text { entheses }\end{array}$ & 100 & Nov 2013 \\
\hline NCT01251614 & $\begin{array}{l}\text { Juvenile chronic } \\
\text { plaque psoriasis }\end{array}$ & $\begin{array}{l}\text { R, DB, PG, } \\
M C\end{array}$ & $\begin{array}{l}\text { Active, not } \\
\text { recruiting }\end{array}$ & III & $\begin{array}{l}\text { Adalimumab } \\
\text { low dose and } \\
\text { standard dose } \\
\text { vs MTX }\end{array}$ & PAS175, PGA, AEs & 111 & $\operatorname{Jan} 2015$ \\
\hline NCT01497717 & $\begin{array}{l}\text { Behcet's disease } \\
\text { and arthritis }\end{array}$ & $\mathrm{OL}$ & Recruiting & III & Adalimumab & Reduction in DAS28 & 15 & Sept 2016 \\
\hline NCT01960790 & $\begin{array}{l}\text { Intestinal } \\
\text { Behçet's disease }\end{array}$ & Observational & Recruiting & $\mathrm{NR}$ & Adalimumab & AEs & 250 & May 2017 \\
\hline
\end{tabular}

$A E$, adverse event; CO, crossover; DAS28, Disease activity score in 28 joints; JIA, juvenile idiopathic arthritis; $M C$, multicentre; MTX, methotrexate; NR, not reported; OL, open-label; PASI75, the proportion of subjects achieving a Psoriasis Area and Severity Index 75 response; PBO, placebo; PC, placebo-controlled; PG, parallel-group; PGA, physicians' global assessment; $R$, randomized; US, ultrasound.

Analyses of data from observational studies have also revealed the incidence of some co-occurring IMIDs. The prospective population-based IBSEN study, for example, showed that peripheral arthritis occurs in about $12 \%$ of patients with IBD in the first year of IBD diagnosis (51). Association of RA with IBD in the same patient is less common and has been described in a few case studies $(9,42)$, although a large cross-sectional study showed that IBD patients were more likely to have other inflammatory diseases, including psoriasis and RA (49). In another large study in 174,476 women with psoriasis and PsA, psoriasis was associated with a significantly increased risk of subsequent Crohn's disease, but not UC, with an increased risk of Crohn's disease among women with psoriasis and PsA (6).

Adalimumab clinical data in patients with two or more IMIDs

As a result of several case reports suggesting the efficacy of adalimumab in co-occurring IMIDs (42), clinical trials, such as the RHAPSODY and CARE 
studies, have investigated the efficacy and tolerability of adalimumab in co-occurring IMIDs $(46,47)$. The preliminary evidence from adalimumab clinical and case studies in patients with two or more immunemediated disorders are summarised in Table 3.

Most data are from the AS RHAPSODY study - a 12-week open-label study of adalimumab in patients with AS. In one analysis, evaluating patients with AS and psoriasis ( $12 \%$ of the cohort), adalimumab treatment resulted in significant improvements in AS clinical parameters (axial disease, peripheral arthritis and enthesitis), but skin changes did not correlate with changes in AS symptoms (52). In addition, among patients with AS, 686 with enthesitis and 281 with peripheral arthritis, adalimumab not only reduced symptoms of active AS but also improved enthesitis and peripheral arthritis (53). In another RHAPSODY analysis in 274 patients with AS and a history of anterior uveitis (AU), adalimumab resulted in a $58 \%$ reduction of uveitis flares; this included a $68 \%$ reduction in patients with a recent history of $\mathrm{AU}, 50 \%$ reduction in patients with symptomatic $\mathrm{AU}$ at baseline and $45 \%$ reduction in patients with chronic uveitis (47).

Several papers have reported adalimumab efficacy in patients with JIA and uveitis. The National Italian Registry has evaluated the safety and efficacy of adalimumab $(n=43)$ and infliximab $(n=48)$ in patients with JIA-AU refractory to standard immunosuppressive treatment and treated $\geq 1$ year, showing that $\mathrm{AU}$ remission was achieved in 55.3\% of patients $(67.4 \%$ vs $42.8 \%$ with adalimumab and infliximab, respectively; $p=0.025$ ) (54).

In a long-term study of the efficacy of adalimumab in 94 patients with JIA and uveitis, adalimumab was effective in the control of JIA and uveitis symptoms, and allowed a reduction in corticosteroid use (55). Adalimumab was also shown to be effective in a patient with psoriatic JIA and uveitis failing NSAID, MTX and etanercept therapy, resulting in remission of both conditions (56) and, in another case report, adalimumab was effective in a patient with AS and Behçet's disease (57).

In a 12-week randomised controlled trial of 208 patients with AS treated with adalimumab, $33 \%$ had uveitis and $8 \%$ had psoriasis at baseline, although the status of the combined conditions at endpoint was not reported (58). An ASAS20
( $\geq 20 \%$ improvement in Assessment in Ankylosing Spondylitis response criteria) response was achieved in $58.2 \%$ of adalimumab-treated patients versus $20.6 \%$ with placebo $(p<0.001)$. Other AS parameters (the Bath Ankylosing Spondylitis Functional Index [BASFI], the Bath Ankylosing Spondylitis Disease Activity Index [BASDAI], and the Bath Ankylosing Spondylitis Metrology Index [BASMI], etc.) were also significantly improved with adalimumab versus placebo (58).

Results from the phase IIIb open-label CARE study in 945 patients with moderate-to-severe Crohn's disease and extraintestinal manifestations (EIMs), showed that adalimumab achieved clinical remission and resolution of EIMs in the majority of patients overall and achieved substantial rates even in patients previously failing infliximab (46).

Finally, a case report of successful adalimumab treatment in a patient with refractory UC and seronegative erosive RA, showed that adalimumab resulted in a sustained remission (42). The use of adalimumab in patients with two or more immunemediated diseases has also shown efficacy in other off-label conditions, but most data are anecdotal and are not the focus of this review. However, this anecdotal evidence has led to a very active Phase III clinical development programme for adalimumab (Table 4).

\section{Adalimumab in paediatric diseases}

There is an urgent need for effective and better tolerated treatments in paediatric patients, as IMIDs are often more severe in younger patients and many are not adequately controlled with the available DMARDs. Furthermore, several biologic agents have tolerability issues that make their use problematic in children. The benign tolerability profile of adalimumab has led to its early approved use in children and adolescents (59-61). Indeed adalimumab is currently approved for use in JIA (formerly designated as juvenile rheumatoid arthritis [JRA]) and paediatric Crohn's disease (5961). However, adalimumab has not been studied in children aged $<2$ years old, and limited data are available in children weighing less than $15 \mathrm{~kg}(21)$.

\section{Juvenile idiopathic arthritis}

JIA is a chronic inflammatory disorder defined 
as arthritis that persists for $\geq 6$ weeks in children and adolescents aged $<16$ years without any other identifiable cause (62). The prevalence of significant paediatric arthritis and other rheumatologic conditions has been estimated in the US at approximately 294,000, based on ICD-9-CM estimates (63). As with other IMIDs, treatment for JIA has evolved from symptom-based treatment, to the use of DMARDs such as MTX, corticosteroids, and the biologic drugs etanercept and adalimumab. Adalimumab has shown excellent efficacy and tolerability in patients with JIA. For example in one study in six patients failing MTX, infliximab and etanercept therapy, adalimumab $24 \mathrm{mg} / \mathrm{m}^{2} /$ week plus MTX resulted in a sustained improvement or remission in three children and was well tolerated (64). In a 16-week, single-arm, openlabel study of adalimumab in 25 Japanese patients with JIA, the American College of Rheumatology (ACR) Pedi30 ( $\geq 30 \%$ improvement in ACR pediatric JIA response criteria) response rates at week 16 were $90 \%$ and $100 \%$ with and without MTX, and the clinical response was maintained up to week 60 in most patients. Of the 25 patients, six patients (all with concomitant MTX therapy) experienced nine serious AEs (65).

\section{Paediatric Crohn's disease}

The majority of children with IBD have Crohn's disease, although paediatric UC and indeterminate colitis are also observed. Crohn's disease is a disorder of the young population, with about a quarter of cases presenting in children and young people (66). Complications, such as impaired growth, delayed puberty and low bone density, are caused by malnutrition in children with active Crohn's disease (67). As with adult Crohn's disease, the prevalence has increased in recent years in developed countries, with one US study estimating the prevalence at almost 5 cases per 100,000 , which is twice that of paediatric UC (68). The burden of disease is probably increasing due in part to a trend towards an earlier age of onset (69) and partly to improved diagnosis (70).

Conventional treatments, such as corticosteroids, immunosuppressants and non-biological DMARDs, are currently employed, as most biological therapies are not approved for use in children (71). Adalimumab has been shown to be effective and well tolerated in children with Crohn's disease $(59,72-$ 75) and is one of only two anti-TNF agents approved for use in paediatric Crohn's disease (the other being infliximab). The clinical efficacy and tolerability of adalimumab was investigated in the 12-month IMAgINE 1 study - a pivotal trial in 192 children with paediatric Crohn's disease (59). After 2 weeks of open-label induction therapy with subcutaneous adalimumab at weeks 0 and $2(160 / 80 \mathrm{mg}$ or $80 / 40$ $\mathrm{mg}$ for body weight $\geq 40 \mathrm{~kg}$ or $<40 \mathrm{~kg}$, respectively), children were assigned to high ( 40 or $20 \mathrm{mg}$ ) or low dose (20 or $10 \mathrm{mg}$ ) adalimumab every other week (eow) for 48 weeks. After 6 months of adalimumab therapy, $33.5 \%$ of patients achieved clinical remission and the treatment was well tolerated, with a safety profile similar to that recorded in adults with Crohn's disease (59). In a 12-month study investigating the effect of adalimumab on growth in 36 children with Crohn's disease, remission was achieved in $78 \%$ and catch-up growth, occurring in $42 \%$ of children with adalimumab, was more likely in those who achieved remission (76).

\section{Pharmacoeconomic considerations}

A Health Technology Assessment (HTA) in RA patients failing one anti-TNF inhibitor showed that, compared with DMARDs, the incremental cost-effectiveness ratios (ICERs) were lowest for adalimumab, followed by etanercept and then infliximab (77). A review of eight pharmacoeconomic studies evaluating the cost of adalimumab, etanercept, and infliximab in the management of RA showed that overall, biologic therapies cost considerably more than traditional DMARDs, but produce more quality-adjusted life-years (QALYs) (78).

Pharmacoeconomic studies with a societal perspective, that take indirect costs and social outcomes such as work productivity into account, indicate that the benefits provided by adalimumab in terms of improved work productivity, for example, could lend to considerable socio-economic benefits compared with conventional treatment in Crohn's disease $(79,80)$.

More recently, an Italian group developed two economic evaluation models $(81,82)$ estimating, in the Social Cost Study (82), the global social cost in terms of lost productivity due to RA, PsA, AS, Crohn's disease and psoriasis, and, in the COVET 
Study (81), estimating the overall economic value of a single multi-indication drug (adalimumab) versus a multi-drug prescription.

Assessment of indirect costs is extremely important when managing chronic diseases. Patients' lost productivity is often overlooked by decisionmakers, although it is fundamental for estimation of the true economic impact of disease. Therefore, the Social Cost Study (82) estimated the social savings obtained with adalimumab compared with standard therapies for treatment of RA, PsA, AS, Crohn's disease and psoriasis, in the Italian population. Five different economic models were developed by external consultants to estimate the cost utility of adalimumab versus standard care for each of the five diseases. Both Italian National Health System (direct costs) and social (direct costs + loss of productivity) perspectives were adopted. For each indication, the models calculated the annual loss of productivity per patient with standard therapy and with adalimumab. A sensitivity analysis, based on the variability of model parameters, was performed in order to assess the robustness of the results. In the base-case scenario, the average annual social cost (weighted for prevalence of eligible patients for biologic treatment of each indication) per patient amounted to $€ 1,421$ if treated with standard care, compared with $€ 744$ with adalimumab. Adalimumab treatment provided an $8.1 \%$ ( $€ 40$ million) reduction in the total social cost, and an annual saving in social costs of $7.0-11.0 \%$, assuming $17 \%$ of market penetration for patients eligible for biologic use. The results showed that adalimumab has a significant impact in reducing social costs for all the indications considered. These aspects, often neglected in decision makers' assessments, should be included in the overall evaluation of benefits of innovative technologies such as biologic drugs.

The value of a drug can also be expressed as the cost needed to increase a unit of health (e.g. QALY); however, summarizing the economic value of a molecule with multiple indications is a complex process. The COVET study provided a comprehensive economic evaluation of adalimumab across all five indications approved at the time of the analysis (81). An algorithm was developed to estimate the total economic value of adalimumab. This value was calculated as the sum of ICERs for treating RA, PsA, AS, Crohn's disease, and psoriasis from an Italian National Health System (NHS) perspective. Estimates of the cost per QALY gained for adalimumab versus standard therapy were derived from previously developed economic models. The sum was weighted according to the prevalence of each of the indications considered. Using a systematic literature review, the cost per QALY gained by using other anti-TNF drugs was extrapolated. Subsequently, a Boston matrix was developed to establish the economic cumulative value, i.e. the relationship between demand (i.e., prevalence of patients treatable with biologics for each disease) and supply (e.g., willingness to pay [WTP] threshold of the healthcare authorities), relative to ICER. Using a societal perspective and the highest value of each model, a one-way sensitivity analysis was performed to test the robustness of the results. The total economic value of adalimumab in Italy amounted to $€ 35,854$ per QALY. The sensitivity analysis showed that the cost per QALY gained ranged from $€ 27,758$ to $€ 40,799$. Analysis of the Boston matrix indicated that, with the exception of psoriasis, the cost per QALY gained by using adalimumab instead of standard therapy was below the common WTP threshold. For psoriasis, the cost per QALY for adalimumab was over the WTP threshold, but this is a situation common to all biologic drugs, and adalimumab has the best cost effectiveness ratio. Overall, in comparison with other biologics, the total economic value of adalimumab was positive and sustainable. This should encourage decision makers to facilitate patient access to this cost-effective treatment. The findings may also promote research to develop innovative molecules that are even more cost effective.

\section{Impact on treatment guidelines}

Current European and Italian guidelines for management of RA, published by the European League Against Rheumatism (EULAR) (16, 83-86), recommend that biologics should be used as secondline therapy only after MTX (or other DMARD) failure. Biological agents should be administered in combination with MTX, in patients failing to respond to non-biologic DMARD within 6 months and when poor prognostic factors are present (84). ACR guidelines for RA treatment, on the other hand 
(87), recommend the use of an anti-TNF, with or without MTX, in patients with early RA (less than 6 months' duration) with high disease activity and poor prognostic features.

Given the benefits demonstrated in early disease (mainly in RA but also in other IMIDs), there is a need for better prognostic indicators and patient risk stratification algorithms to allow identification and selection of those most likely to benefit from firstline adalimumab therapy - either as monotherapy or in combination with MTX. Long-term outcome studies are also needed to provide data for prognostic, predictive and pharmacoeconomic analyses to inform future treatment guidelines.

Although the drug costs of biological agents is considerably higher than that of non-biological DMARDs, many of these extra costs are offset by savings in terms of reduced hospitalisation, reduced number of outpatient visits, etc. In this respect, further research and data are required to demonstrate the overall cost-effectiveness of anti-TNFs from both a healthcare and socioeconomic perspective, the latter taking into account the substantial indirect cost savings resulting from improved work productivity, reduced absenteeism, reduced care costs and assistance with daily living, and improved patient quality of life (88).

The fact that adalimumab has the widest range of approved indications, including many disorders often presenting together in the same patient, may further improve the cost effectiveness of adalimumab, since the use of a multi-indication drug to treat two or more indications in the same patient would decrease considerably the drug burden. This would make adalimumab very valuable for treatment of cooccurring IMIDs.

\section{CONCLUSIONS}

Current data demonstrate that adalimumab is a valuable resource in the management of IMIDs. It has proven efficacy and tolerability in a wide range of indications, many of which can be found in the same patient due to their common pathogenesis, and it has been shown also to be suitable in the management of paediatric IMIDs. Comparisons of clinical utility and cost-effectiveness support the view that adalimumab is a valid treatment choice in a wide range of patients. Recent Italian economic studies provide a first indication of the total economic value of adalimumab, showing it to be below the threshold value for health care interventions for all the main indications. In addition, analysis of indirect costs shows that adalimumab significantly reduces societal costs associated with RA, PsA, AS, Crohn's disease and psoriasis.

As a multi-indication drug, adalimumab is expected to have greater pharmacoeconomic benefits in comparison with biologics with a more restricted range of indications, when used to treat two or more indications in the same patient. However, taking all costs into account, the current economic differences appear to be marginal in clinical practice; this may be due to difference in recorded indications. For example, it is unavoidable that the more recently marketed drugs have fewer recorded indications due to their 'youth' in the market. Comparison among indications makes sense only between adalimumab and etanercept, where the lack of effectiveness of etanercept in granulomatous diseases (e.g. Crohn's disease) is certain. However, despite rational aetiopathogenic considerations, information comparing one drug with another in patients with specific disease associations is limited.

Additional research is required to better identify patients who may benefit most from treatments with adalimumab, as well as to expand the range of use of this versatile TNF inhibitor.

\section{ACKNOWLEDGEMENTS}

Medical writing assistance was provided by Mary Hines on behalf of HPS, Health Publishing \& Services Srl, Milan. The assistance was supported by finding from AbbVie Srl, Italy.

$\mathrm{CB}$ has been member of advisory boards for Abbvie.

$\mathrm{RC}$ has been member of advisory boards for Abbvie

GG has received advisory/speaker honoraria and/or research funding from AbbVie, Almirall, Boehringer Ingelheim, Celgene, Dompè, Eli-Lilly, Galderma, GSK, Janssen, Leo Pharma, Otsuka, Merck-Serono, Maruho, MSD, Novartis and Pfizer.

AA has received consulting fees from Abbvie, Hospira, Lilly and MSD, and lecture fees from 
Abbvie, Chiesi, Ferring, MSD, Nycomed and Otsuka.

$\mathrm{AM}$ has received consulting fees and/or speaker fees from Abbvie, Pfizer, Merck, UCB.

The other authors have no conflicts of interest to declare.

\section{REFERENCES}

1. Kuek A., B.L. Hazleman, A.J. Ostor. Immunemediated inflammatory diseases (IMIDs) and biologic therapy: a medical revolution. Postgrad Med J 2007; 83:251-60.

2. Zhernakova A., C.C. van Diemen, C. Wijmenga. Detecting shared pathogenesis from the shared genetics of immune-related diseases. Nat Rev Genet 2009; 10:43-55.

3. Lees C.W., J.C. Barrett, M. Parkes, J. Satsangi. New IBD genetics: common pathways with other diseases. Gut 2011; 60:1739-53.

4. Cohen A.D., J. Dreiher, S. Birkenfeld. Psoriasis associated with ulcerative colitis and Crohn's disease. J Eur Acad Dermatol Venereol 2009; 23:561-5.

5. Najarian D.J., A.B. Gottlieb. Connections between psoriasis and Crohn's disease. J Am Acad Dermatol 2003; 48:805-21; quiz 22-4.

6. Li W.Q., J.L. Han, A.T. Chan, A.A. Qureshi. Psoriasis, psoriatic arthritis and increased risk of incident Crohn's disease in US women. Ann Rheum Dis 2012.

7. Mosquera-Martinez J.A. Rheumatoid arthritis associated with ulcerative colitis. Ann Rheum Dis 2001; 60:1155.

8. Boyer F., E. Fontanges, P. Miossec. Rheumatoid arthritis associated with ulcerative colitis: a case with severe flare of both diseases after delivery. Ann Rheum Dis 2001; 60:901.

9. Cruz V.A., L. Yamaguchi, C.N. Ribeiro, O. Magalhaes Vde, J. Rego, N.A. Silva. Ulcerative colitis and rheumatoid arthritis: a rare association-case report. Rev Bras Reumatol 2012; 52:648-50.

10. Aydin Y., L. Ozcakar, M. Yildiz, A. Akinci. Liaison between rheumatoid arthritis and ulcerative colitis. Rheumatol Int 2003; 23:47-8.

11. Breedveld F.C., M.H. Weisman, A.F. Kavanaugh et al. The PREMIER study: A multicenter, randomized, double-blind clinical trial of combination therapy with adalimumab plus methotrexate versus methotrexate alone or adalimumab alone in patients with early, aggressive rheumatoid arthritis who had not had previous methotrexate treatment. Arthritis Rheum 2006; 54:26-37.

12. Lovell D.J., N. Ruperto, S. Goodman et al. Adalimumab with or without methotrexate in juvenile rheumatoid arthritis. The New England journal of medicine 2008; 359:810-20.

13. Nash P.T., T.H. Florin. Tumour necrosis factor inhibitors. Med J Aust 2005; 183:205-8.

14. Silva L.C., L.C. Ortigosa, G. Benard. Anti-TNFalpha agents in the treatment of immune-mediated inflammatory diseases: mechanisms of action and pitfalls. Immunotherapy $2010 ; 2: 817-33$.

15. Firestein G.S., M. Corr. Common mechanisms in immune-mediated inflammatory disease. $\mathrm{J}$ Rheumatol Suppl 2005; 73:8-13; discussion 29-30.

16. Furst D.E., E.C. Keystone, J. Braun et al. Updated consensus statement on biological agents for the treatment of rheumatic diseases, 2011. Ann Rheum Dis 2012; 71 Suppl 2:i2-45.

17. Taylor P.C., R.O. Williams, M. Feldmann. Tumour necrosis factor alpha as a therapeutic target for immune-mediated inflammatory diseases. Curr Opin Biotechnol 2004; 15:557-63.

18. Savarino E., G. Bodini, P. Dulbecco et al. Adalimumab Is More Effective Than Azathioprine and Mesalamine at Preventing Postoperative Recurrence of Crohn's Disease: A Randomized Controlled Trial. Am J Gastroenterol 2013.

19. West C., S. Narahari, J. O'Neill et al. Adherence to adalimumab in patients with moderate to severe psoriasis. Dermatol Online J 2013; 19:18182.

20. Taylor P.C. Pharmacology of TNF blockade in rheumatoid arthritis and other chronic inflammatory diseases. Curr Opin Pharmacol 2010; 10:308-15.

21. Thalayasingam N., J.D. Isaacs. Anti-TNF therapy. Best Pract Res Clin Rheumatol 2011; 25:549-67.

22. Murdaca G., B.M. Colombo, F. Puppo. Adalimumab for the treatment of immune-mediated diseases: an update on old and recent indications. Drugs Today (Barc) 2011; 47:277-88.

23. Keystone E.C., A.F. Kavanaugh, J.T. Sharp et al. Radiographic, clinical, and functional outcomes of 
treatment with adalimumab (a human anti-tumor necrosis factor monoclonal antibody) in patients with active rheumatoid arthritis receiving concomitant methotrexate therapy: a randomized, placebocontrolled, 52-week trial. Arthritis Rheum 2004; 50:1400-11.

24. Weinblatt M.E., E.C. Keystone, D.E. Furst et al. Adalimumab, a fully human anti-tumor necrosis factor alpha monoclonal antibody, for the treatment of rheumatoid arthritis in patients taking concomitant methotrexate: the ARMADA trial. Arthritis Rheum 2003 ; 48:35-45.

25. van der Heijde D., M.H. Schiff, J. Sieper et al. Adalimumab effectiveness for the treatment of ankylosing spondylitis is maintained for up to 2 years: long-term results from the ATLAS trial. Ann Rheum Dis 2009; 68:922-9.

26. Rudwaleit M., F. Van den Bosch, M. Kron, S. Kary, H. Kupper. Effectiveness and safety of adalimumab in patients with ankylosing spondylitis or psoriatic arthritis and history of anti-tumor necrosis factor therapy. Arthritis Res Ther 2010;12:R117.

27. Sieper J., D. van der Heijde, M. Dougados et al. Efficacy and safety of adalimumab in patients with non-radiographic axial spondyloarthritis: results of a randomised placebo-controlled trial (ABILITY-1). Ann Rheum Dis 2013; 72:815-22.

28. Gladman D.D., P.J. Mease, C.T. Ritchlin et al. Adalimumab for long-term treatment of psoriatic arthritis: forty-eight week data from the adalimumab effectiveness in psoriatic arthritis trial. Arthritis Rheum 2007; 56:476-88.

29. Gordon K.B., R.G. Langley, C. Leonardi et al. Clinical response to adalimumab treatment in patients with moderate to severe psoriasis: double-blind, randomized controlled trial and open-label extension study. J Am Acad Dermatol 2006; 55:598-606.

30. Saurat J.H., G. Stingl, L. Dubertret et al. Efficacy and safety results from the randomized controlled comparative study of adalimumab vs. methotrexate vs. placebo in patients with psoriasis (CHAMPION). Br J Dermatol 2008; 158:558-66.

31. Colombel J.F., W.J. Sandborn, P. Rutgeerts et al. Adalimumab for maintenance of clinical response and remission in patients with Crohn's disease: the CHARM trial. Gastroenterology 2007; 132:52-65.
32. Schreiber S., W. Reinisch, J.F. Colombel et al. Subgroup analysis of the placebo-controlled CHARM trial: increased remission rates through 3 years for adalimumab-treated patients with early Crohn's disease. J Crohns Colitis 2013; 7:213-21.

33. Sandborn W.J., G. van Assche, W. Reinisch et al. Adalimumab induces and maintains clinical remission in patients with moderate-to-severe ulcerative colitis. Gastroenterology 2012; 142:25765 e $1-3$.

34. Sandborn W.J., J.F. Colombel, G. D'Haens et al. One-year maintenance outcomes among patients with moderately-to-severely active ulcerative colitis who responded to induction therapy with adalimumab: subgroup analyses from ULTRA 2 . Aliment Pharmacol Ther 2013; 37:204-13.

35. Burmester G.R., P. Mease, B.A. Dijkmans et al. Adalimumab safety and mortality rates from global clinical trials of six immune-mediated inflammatory diseases. Ann Rheum Dis 2009; 68:1863-9.

36. Burmester G.R., R. Panaccione, K.B. Gordon, M.J. McIlraith, A.P. Lacerda. Adalimumab: long-term safety in 23458 patients from global clinical trials in rheumatoid arthritis, juvenile idiopathic arthritis, ankylosing spondylitis, psoriatic arthritis, psoriasis and Crohn's disease. Ann Rheum Dis 2012.

37. Burmester G.R., R. Panaccione, K.B. Gordon, M.J. McIlraith, A.P. Lacerda. Adalimumab: long-term safety in 23458 patients from global clinical trials in rheumatoid arthritis, juvenile idiopathic arthritis, ankylosing spondylitis, psoriatic arthritis, psoriasis and Crohn's disease. Ann Rheum Dis 2013; 72:51724.

38. Garces S., J. Demengeot, E. Benito-Garcia. The immunogenicity of anti-TNF therapy in immunemediated inflammatory diseases: a systematic review of the literature with a meta-analysis. Ann Rheum Dis 2012.

39. Spinelli F.R., G. Valesini. Immunogenicity of antitumour necrosis factor drugs in rheumatic diseases. Clin Exp Rheumatol 2013.

40. Jani M., A. Barton, R.B. Warren, C.E. Griffiths, H. Chinoy. The role of DMARDs in reducing the immunogenicity of TNF inhibitors in chronic inflammatory diseases. Rheumatology (Oxford) 2013. 
41. Jullien D. [Anti-drug antibodies, auto-antibodies and biotherapy in psoriasis]. Ann Dermatol Venereol 2012; 139 Suppl 2:S58-67.

42. Andrisani G., E. Gremese, L. Guidi et al. Achievement of sustained deep remission with adalimumab in a patient with both refractory ulcerative colitis and seronegative erosive rheumatoid arthritis. In press 2013.

43. Garces S., M. Antunes, E. Benito-Garcia, J.C. da Silva, L. Aarden, J. Demengeot. A preliminary algorithm introducing immunogenicity assessment in the management of patients with RA receiving tumour necrosis factor inhibitor therapies. Ann Rheum Dis 2013.

44. Vincent F.B., E.F. Morand, K. Murphy, F. Mackay, X. Mariette, C. Marcelli. Antidrug antibodies (ADAb) to tumour necrosis factor (TNF)-specific neutralising agents in chronic inflammatory diseases: a real issue, a clinical perspective. Ann Rheum Dis 2013; 72:165-78.

45. Ordas I., D.R. Mould, B.G. Feagan, W.J. Sandborn. Anti-TNF monoclonal antibodies in inflammatory bowel disease: pharmacokinetics-based dosing paradigms. Clinical pharmacology and therapeutics 2012; 91:635-46.

46. Lofberg R., E.V. Louis, W. Reinisch, A.M. Robinson, M. Kron, A. Camez, P.F. Pollack. Adalimumab produces clinical remission and reduces extraintestinal manifestations in Crohn's disease: results from CARE. Inflamm Bowel Dis 2012; 18:1-9.

47. Rudwaleit M., E. Rodevand, P. Holck, J. Vanhoof, M. Kron, S. Kary, H. Kupper. Adalimumab effectively reduces the rate of anterior uveitis flares in patients with active ankylosing spondylitis: results of a prospective open-label study. Ann Rheum Dis 2009; 68:696-701.

48. Rebelo A., S. Leite, J. Cotter. Association of ankylosing spondylitis and Crohn's disease successfully treated with infliximab. BioDrugs 2010; 24 Suppl 1:37-9.

49. Weng X., L. Liu, L.F. Barcellos, J.E. Allison, L.J. Herrinton. Clustering of inflammatory bowel disease with immune mediated diseases among members of a northern california-managed care organization. Am J Gastroenterol 2007; 102:1429-35.

50. Kappelman M.D., J.A. Galanko, C.Q. Porter, R.S. Sandler. Association of paediatric inflammatory bowel disease with other immune-mediated diseases. Arch Dis Child 2011; 96:1042-6.

51. Palm O., B. Moum, J. Jahnsen, J.T. Gran. The prevalence and incidence of peripheral arthritis in patients with inflammatory bowel disease, a prospective population-based study (the IBSEN study). Rheumatology (Oxford) 2001; 40:1256-61.

52. Braun J., M. Rudwaleit, S. Kary, M. Kron, R.L. Wong, H. Kupper. Clinical manifestations and responsiveness to adalimumab are similar in patients with ankylosing spondylitis with and without concomitant psoriasis. Rheumatology (Oxford) 2010; 49:1578-89.

53. Rudwaleit M., P. Claudepierre, M. Kron, S. Kary, R. Wong, H. Kupper. Effectiveness of adalimumab in treating patients with ankylosing spondylitis associated with enthesitis and peripheral arthritis. Arthritis Res Ther 2010; 12:R43.

54. Zannin M.E., C. Birolo, V.M. Gerloni et al. Safety and efficacy of infliximab and adalimumab for refractory uveitis in juvenile idiopathic arthritis: l-year followup data from the Italian Registry. $J$ Rheumatol 2013; 40:74-9.

55. Kotaniemi K., H. Saila, H. Kautiainen. Long-term efficacy of adalimumab in the treatment of uveitis associated with juvenile idiopathic arthritis. Clin Ophthalmol 2011; 5:1425-9.

56. Moretti D., I. Cianchi, G. Vannucci, R. Cimaz, G. Simonini. Psoriatic juvenile idiopathic arthritis associated with uveitis: a case report. Case Rep Rheumatol 2013; 2013:595890.

57. Yildiz N., H. Alkan, F. Ardic, O. Topuz. Successful treatment with adalimumab in a patient with coexisting Behcet's disease and ankylosing spondylitis. Rheumatol Int 2010; 30:1511-4.

58. van der Heijde D., A. Kivitz, M.H. Schiff et al. Efficacy and safety of adalimumab in patients with ankylosing spondylitis: results of a multicenter, randomized, double-blind, placebo-controlled trial. Arthritis Rheum 2006; 54:2136-46.

59. Hyams J.S., A. Griffiths, J. Markowitz et al. Safety and efficacy of adalimumab for moderate to severe Crohn's disease in children. Gastroenterology 2012; 143:365-74 e2.

60. Tynjala P., K. Kotaniemi, P. Lindahl, K. Latva, K. Aalto, V. Honkanen, P. Lahdenne. Adalimumab 
in juvenile idiopathic arthritis-associated chronic anterior uveitis. Rheumatology (Oxford) 2008; 47:339-44

61. Yokota S., T. Imagawa, T. Murata et al. Guidance on the use of adalimumab for juvenile idiopathic arthritis in Japan. Modern rheumatology / the Japan Rheumatism Association 2012; 22:491-7.

62. Shenoi S., C.A. Wallace. Tumor necrosis factor inhibitors in the management of juvenile idiopathic arthritis: an evidence-based review. Paediatr Drugs 2010; 12:367-77.

63. Sacks J.J., C.G. Helmick, Y.H. Luo, N.T. Ilowite, S. Bowyer. Prevalence of and annual ambulatory health care visits for pediatric arthritis and other rheumatologic conditions in the United States in 2001-2004. Arthritis Rheum 2007; 57:1439-45.

64. Katsicas M.M., R.A. Russo. Use of adalimumab in patients with juvenile idiopathic arthritis refractory to etanercept and/or infliximab. Clin Rheumatol 2009; 28:985-8.

65. Imagawa T., S. Takei, H. Umebayashi et al. Efficacy, pharmacokinetics, and safety of adalimumab in pediatric patients with juvenile idiopathic arthritis in Japan. Clin Rheumatol 2012; 31:1713-21.

66. Heyman M.B., B.S. Kirschner, B.D. Gold et al. Children with early-onset inflammatory bowel disease (IBD): analysis of a pediatric IBD consortium registry. J Pediatr 2005; 146:35-40.

67. Motil K.J., R.J. Grand, L. Davis-Kraft, L.L. Ferlic, E.O. Smith. Growth failure in children with inflammatory bowel disease: a prospective study. Gastroenterology 1993; 105:681-91.

68. Kugathasan S., R.H. Judd, R.G. Hoffmann et al. Epidemiologic and clinical characteristics of children with newly diagnosed inflammatory bowel disease in Wisconsin: a statewide population-based study. $\mathbf{J}$ Pediatr 2003; 143:525-31.

69. Assa A., C. Hartman, B. Weiss et al. Long-term outcome of tumor necrosis factor alpha antagonist's treatment in pediatric Crohn's disease. J Crohns Colitis 2012.

70. Pallotta N., F. Civitelli, G. Di Nardo et al. Small intestine contrast ultrasonography in pediatric Crohn's disease. J Pediatr 2013; 163:778-84 e1.

71. Markowitz J. Current treatment of inflammatory bowel disease in children. Dig Liver Dis 2008; 40:16-21.
72. Martin-de-Carpi J., N. Pociello, V. Varea. Long-term efficacy of adalimumab in paediatric Crohn's disease patients naive to other anti-TNF therapies. J Crohns Colitis 2010; 4:594-8.

73. Rosh J.R., T. Lerer, J. Markowitz et al. Retrospective Evaluation of the Safety and Effect of Adalimumab Therapy (RESEAT) in pediatric Crohn's disease. Am J Gastroenterol 2009; 104:3042-9.

74. Viola F., F. Civitelli, G. Di Nardo et al. Efficacy of adalimumab in moderate-to-severe pediatric Crohn's disease. Am J Gastroenterol 2009; 104:2566-71.

75. Rosenbach Y., C. Hartman, R. Shapiro, A. Hirsch, Y. Avitzur, R. Shamir. Adalimumab treatment in children with refractory Crohn's disease. Dig Dis Sci 2010; 55:747-53.

76. Malik S., S.F. Ahmed, M.L. Wilson et al. The effects of anti-TNF-alpha treatment with adalimumab on growth in children with Crohn's disease (CD). J Crohns Colitis 2012; 6:337-44.

77. Malottki K., P. Barton, A. Tsourapas et al. Adalimumab, etanercept, infliximab, rituximab and abatacept for the treatment of rheumatoid arthritis after the failure of a tumour necrosis factor inhibitor: a systematic review and economic evaluation. Health Technol Assess 2011; 15:1-278.

78. Doan Q.V., C.F. Chiou, R.W. Dubois. Review of eight pharmacoeconomic studies of the value of biologic DMARDs (adalimumab, etanercept, and infliximab) in the management of rheumatoid arthritis. J Manag Care Pharm 2006; 12:555-69.

79. Binion D.G., E. Louis, B. Oldenburg, P. Mulani, A.G. Bensimon, M. Yang, J. Chao. Effect of adalimumab on work productivity and indirect costs in moderate to severe Crohn's disease: a meta-analysis. Can J Gastroenterol 2011; 25:492-6.

80. Louis E., R. Lofberg, W. Reinisch et al. Adalimumab improves patient-reported outcomes and reduces indirect costs in patients with moderate to severe Crohn's disease: results from the CARE trial. J Crohns Colitis 2013; 7:34-43.

81. Mennini F.S., A. Marcellusi, L. Gitto, P. Giannantoni, G. Favato. Comprehensive value estimation of adalimumab-based treatments: covet study [PHP36] Value Health 2012; 15:A19.

82. Marcellusi A., L. Gitto, P. Giannantoni, S. Russo, F.S. Mennini. Social impact of adalimumab in the Italian 
perspective [PIH26]. Value Health 2012; 15:A540.

83. Smolen J.S., R. Landewe, F.C. Breedveld et al. EULAR recommendations for the management of rheumatoid arthritis with synthetic and biological disease-modifying antirheumatic drugs. Ann Rheum Dis 2010; 69:964-75.

84. European League Against Rheumatism (EULAR). EULAR issues updated rheumatoid arthritis (RA) management recommendations. 2013 [cited 2013 October 11]; Available from: http://www.eular. org/myUploadData/files/EULAR\%20RA\%20 recommendations\%20FINAL.pdf

85. Smolen J.S., R. Landewe, F.C. Breedveld et al. EULAR recommendations for the management of rheumatoid arthritis with synthetic and biological disease-modifying antirheumatic drugs: 2013 update.
Ann Rheum Dis 2013.

86. Caporali R., F. Conti, S. Alivernini et al. Recommendations for the use of biologic therapy in rheumatoid arthritis: update from the Italian Society for Rheumatology I. Efficacy. Clin Exp Rheumatol 2011; 29:S7-14.

87. Singh J.A., D.E. Furst, A. Bharat et al. 2012 update of the 2008 American College of Rheumatology recommendations for the use of disease-modifying antirheumatic drugs and biologic agents in the treatment of rheumatoid arthritis. Arthritis Care Res (Hoboken) 2012; 64:625-39.

88. Bansback N., A. Brennan, A.H. Anis. A pharmacoeconomic review of adalimumab in the treatment of rheumatoid arthritis. Expert Rev Pharmacoecon Outcomes Res 2005; 5:519-29. 